\title{
METABOLIC SYNDROME IN COLLECTION AND DISPOSAL OF SOLID WASTE SECTOR
}

\section{HASAN HÜSEYIN EKER ${ }^{1}$, RECEP YILMAZ BAYRAKTARLI' ${ }^{2}$, HALIM ISSSEVER ${ }^{3}$, TÜMER ULAŞ ${ }^{3}$, MUSTAFA ERELEL ${ }^{4}$, ALI ESER ${ }^{5}$, KÜRŞAT ÖZDILLI' ${ }^{6}$, AND ACLAN ÖZDER ${ }^{7}$}

${ }^{1}$ University of Gumushane, Gumushane, Turkey

Higher School of Health Sciences

${ }^{2}$ Istanbul Environmental Protection and Waste Material Recycling Industry and Trading Company, Istanbul, Turkey

${ }^{3}$ Istanbul University, Faculty of Medicine, Istanbul

Turkey Department of Public Health

${ }^{4}$ Istanbul University, Faculty of Medicine, Istanbul, Turkey

Department of Chest Diseases

${ }^{5}$ Istanbul Kucukkoy Bilge Hospital, Istanbul, Turkey

${ }^{6}$ Istanbul University Florence Nightingale School of Nursing, Istanbul, Turkey

${ }^{7}$ Istanbul Metropolitan City Municipality, Istanbul, Turkey

IETT General Directorate

\begin{abstract}
Objectives: This study aims to assess the frequency and factors relevant to metabolic syndrome in workers employed in the collection and disposal of solid waste sector. Materials and Methods: This cross-sectional study was conducted in the major solid waste collecting and disposal company named ISTAÇ AŞ (İstanbul Environmental Protection and Waste Processing Corporation) in Istanbul, Turkey. All 715 male employees of the company were included in the study without sampling. The study was completed with 619 subjects. Since it was a small group, female workers were not taken into account in the study. Metabolic syndrome frequency was investigated according to the NCEP-ATP III criteria including the levels of systolic and diastolic blood pressure, waist perimeter, HDL, triglyceride, fasting blood glucose values. Results: Metabolic syndrome was present in $40.9 \%$ of participating employees. Metabolic syndrome was more common in those working in the excavation field (54.0\%), such as caterpillar operators $(56.5 \%)$, and less common in employees working in administrative offices, such as office staff or managers, who were under 35 years old and who had been working for less than 10 years $(p<0.05)$. Employees working in work stations other than administrative offices had a 2.60 times higher risk compared to those working in administrative offices. Conclusions: Metabolic syndrome may be related to work station, job, age and period worked by the subjects.
\end{abstract}

Key words:

Metabolic syndrome, Disposal, Solid waste workers

Received: June 30, 2011. Accepted: September 26, 2011.

Address reprint request to A. Özder, IETT Ayazaga Garaji, Kemerburgaz Yolu, No: 4-16, Ayazaga, Sisli, Istanbul, Turkey (e-mail: aclan.ozder@aol.com). 


\section{INTRODUCTION}

The aim of occupational medicine is to improve health capacity of employees, prevent hazards that may arise from the workplace environment and minimize the threats and hazards that cannot be prevented, as well as to install an employee in a job appropriate for his/her anatomic and psychological characteristics. Following that procedure, a series of processes, such as periodical examinations for risk factors is essential to make the health status of an employee even better. One of these risks is metabolic syndrome arising from a different set of cardiovascular risk factor components such as impaired insulin resistance and glucose intolerance, diabetes mellitus, obesity, abdominal fat accumulation, dyslipidemia and hypertension [1].

Eskil Kylin first defined metabolic syndrome as accumulation of cardiovascular risk factors naming them together in 1923 [2].

Gerald Reaven named this syndrome "syndrome X" in 1988. He emphasized the importance of a close relationship between the resistance of insulin and the gathering of the mentioned risk factors (hypertension, glucose intolerance, hypertriglyceridemia, low HDL values) [3].

Ferranrini stated that abnormalities which are components of this syndrome result from insulin resistance and thus, the syndrome was named the insulin resistance syndrome in 1991 [4].

Metabolic syndrome is a serious public health issue as it causes cardiovascular diseases, increases the risk of diabetes and has a relatively high prevalence [5]. Mortality and morbidity are significantly increased in cardiovascular diseases accompanied by metabolic syndrome [6]. Zeller found in his investigations metabolic syndrome defined by the NCEP ATP III criteria in $46 \%$ of 633 patients who had acute myocardial infarction (AMI) [7].

This study was conducted to explore the frequency and factors relevant to metabolic syndrome in workers employed in the collecting and disposal of solid waste sector, considered as one of the most dangerous jobs.

\section{MATERIALS AND METHODS}

This study is a cross-sectional study conducted between March and July, 2009. The study was conducted in the major solid waste collecting and disposal company ISTAÇ AŞ (İstanbul Environmental Protection and Waste Processing Corporation) of Istanbul Metropolitan Municipality. All 715 employees of the company were included in the study without sampling. Permission was taken from company managers and employees who volunteered in participating. 68 employees did not agree to participate and the study was completed with 619 employees. Since it was a small group, female workers were not included in the study and 5 employees quit their job for various reasons. Occupational classification of employees was as follows: office and administrative staff (office staff, advisor, lawyer, general manager, occupational physician, coordinator, unit manager, engineer, healthcare staff, specialist refectory supervisor); caterpillar operators and drivers (caterpillar operator, driver); security staff and field control employees (control overseer, control employee, shift supervisor) and unqualified-master workers. Solid waste storage areas (combustion facility, Asian and European storage areas, Hasdal energy field compost facility, coal storage room, machinery maintenance room), excavation, medical waste disposal area, administrative office (research and development, chieftaincies, security personnel, drivers [except caterpillar operators]), naval services (Port of Haydarpaşa and coast cleaning) and street-avenues scavenging (Asian and European main arteries) were classified as work stations. As for age groups $(<35$, between 35 and 44, and $>45$ years of age) and time worked (less than 10 years and more than 10 years), classifications were made as described above.

The NCEP-ATP criteria have been used as diagnostic criteria for metabolic syndrome in many studies. We, too, prefer to use the NCEP-ATP criteria for the diagnosis of metabolic syndrome, because the International Diabetes 
Society uses them as well, and therefore, the comparisons can be more sound. In our study, the albumin/creatinine ratio in urine and waist/hip ratio were not measured $[8,9]$. The NCEP-ATP III criteria for metabolic syndrome diagnosis:

1. Blood pressure level at rest being $\geq 130 / 85 \mathrm{mmHg}$ or receiving antihypertensive treatment,

2. Fasting glucose level being $\geq 110 \mathrm{mg} / \mathrm{dl}$ or the presence of diabetes mellitus,

3. HDL level being $<40 \mathrm{mg} / \mathrm{dl}$ in males, and $<50 \mathrm{mg} / \mathrm{dl}$ in females,

4. Triglyceride level being $\geq 150 \mathrm{mg} / \mathrm{dl}$,

5. Waist perimeter being $>102 \mathrm{~cm}$ in males, and $>88 \mathrm{~cm}$ in females.

The presence of three or more of these five criteria has been considered as metabolic syndrome [1,10,11].

(In this study, 27 workers were taking antidiabetic and 38 workers were taking antihypertensive medication). For the purpose of the research presented in this paper, mobile exploration vehicles were used while reaching the study sites and the obtained blood specimens were transferred within a short period of time to an established laboratory liable to an international audit (BIO-RAD EQAS). For biochemical investigations, blood samples were taken following a 12-hour fasting period and then assayed. Besides these, all measurements concerning the employees were completed in addition to blood pressure and waist perimeter measurements essential for defined metabolic syndrome diagnosis according to the NCEP-ATP III criteria. Blood pressure was taken following a 10- to 15-minute rest from the left arm with digital tensiometers (Omron M6 Comfort, Intelli-Sense, Omron Healthcare Co, Kyoto, Japan). The body weight was measured when the subjects were wearing light clothes with the use of the same digital gravimeter. Waist perimeter was measured on the line under the last rib and over the iliac crest following the normal expansion while the workers were undressed. Height was measured and recorded by us using a standard meter while the workers were standing bare-footed.

\section{Ethics}

We did not obtain any ethical approval since the study was a cross-sectional type of study and not an experimental one.

\section{Statistics}

Continuous variables are presented as average $\pm \mathrm{SD}$, while categorical variables are presented in percentages. As for statistical analyses, parametric independent samples t-test was used for the analyses between the two groups that showed appropriateness for normal distribution, Mann-Whitney U test was used for the groups that did not hold appropriateness for normal distribution and chi-square test was used for the comparison of categorical variables. An analysis with logistic regression was done while accepting the NCEP-ATP criteria as dependent variables and job, work station, age and the period worked as independent ones. Statistical significance was accepted as $\mathrm{p}<0.05$.

\section{RESULTS}

619 participants were males and the mean age was 40.01 \pm 7.17. $92.7 \%$ of workers in administrative offices were high-school graduates or had higher education, while just $30.6 \%$ of non-office workers were high-school graduates or had higher education. Anthropometric and biochemical features of the employees participating in the study are presented in Table 1.

Metabolic syndrome prevalence was found to equal $40.9 \%$ according to the ATP III criteria among the workers included in the study. Among metabolic syndrome components hypertriglyceridemia was the most frequent one $(57.7 \%)$ (Table 2). 
Table 1. Anthropometric and biochemical features of employees participating in the study

\begin{tabular}{lc}
\hline \multicolumn{1}{c}{ Variables } & Workers \\
\hline Study group [n (\%)] & $619(96.4)$ \\
Age (years) & $40.01 \pm 7.17$ \\
Systolic blood pressure (mm Hg) & $127.50 \pm 18.60$ \\
Diastolic blood pressure (mm Hg) & $82.33 \pm 12.87$ \\
Body mass index ( $\left.\mathrm{kg} / \mathrm{m}^{2}\right)$ & $28.72 \pm 4.02$ \\
Waist perimeter (cm) & $98.05 \pm 10.95$ \\
Total cholesterol (mg/dl) & $214.97 \pm 45.740$ \\
HDL cholesterol (mg/dl) & $39.51 \pm 8.568$ \\
Triglyceride (mg/dl) & $191.02 \pm 110.532$ \\
Fasting glucose (mg/dl) & $87.16 \pm 29.293$ \\
Normal weight [n (\%)] & $106(17.1)$ \\
Mildly overweight [n (\%)] & $295(47.7)$ \\
Obese [n (\%)] & $177(28.6)$ \\
Morbidly obese [n (\%)] & $41(6.6)$ \\
Smoking (never) [n (\%)] & $351(56.7)$ \\
Smoking (for smokers) (n) & $17.43 \pm 7.225$ \\
\hline
\end{tabular}

Table 2. Dispersion of metabolic syndrome components

\begin{tabular}{lc}
\hline \multicolumn{1}{c}{ Variables } & Workers \\
& $\mathrm{N}=619$ \\
{$[\mathrm{n}(\%)]$} \\
\hline High blood pressure & $357(57.7)$ \\
Low HDL cholesterol & $357(57.7)$ \\
Hyperglycemia & $39(6.3)$ \\
Abdominal obesity & $230(37.2)$ \\
Hypertriglyceridemia & $366(59.1)$ \\
\hline
\end{tabular}

While in $11.0 \%$ of the workers there was no metabolic syndrome component observed, $23.6 \%$ had three, $15.3 \%$ had four and $1.9 \%$ had five components (Table 3 ). As for the work stations of employees, metabolic syndrome (MS) was seen mostly in workers employed at excavation sites $(54.0 \%)$. There was a statistically significant difference
Table 3. Dispersion of metabolic syndrome components

\begin{tabular}{lrc}
\hline \multirow{2}{*}{$\begin{array}{c}\text { Number of } \\
\text { components }\end{array}$} & \multicolumn{2}{c}{ Workers } \\
\cline { 2 - 3 } Normal healthy & \multicolumn{1}{c}{$\mathrm{n}$} & $\%$ \\
1 component & 125 & 11.0 \\
2 components & 173 & 20.2 \\
3 components & 146 & 27.9 \\
4 components & 95 & 23.6 \\
5 components & 12 & 15.3 \\
Total & 619 & 1.9 \\
\hline
\end{tabular}

between work station and metabolic syndrome presence $(\mathrm{p}<0.05)$ (Table 4).

Metabolic syndrome was detected in $45 \%$ of the workers involved in the waste processing-related activities while, it equaled $26 \%$ in administrative staff. This difference proved to be statistically significant $(\mathrm{p}<0.05)$ (Table 5). Employees working in work stations other than the administrative office had a 2.60 higher risk of metabolic syndrome compared to those working in the office (Table 6). Employees dealing with waste processing activities had 2.60 times more risk of developing metabolic syndrome than those working in the office (GA 95\%) (Table 6).

Considering the occupation of employees, metabolic syndrome was mostly seen in those who worked as caterpillar operators (56.5\%) (Table 4). As for the occupation of workers, there was a statistically significant difference concerning jobs and metabolic syndrome $(p<0.05)$, and office staff and managers had metabolic syndrome less frequently compared to others. Metabolic syndrome was more frequent among those under 35 years of age and those whose time worked was over 10 years $(p<0.05)$. Those who had worked for more than 10 years had a 1.41 times higher risk of developing metabolic syndrome compared to those who had been working for less than 10 years (Table 6). 
Table 4. Dispersion of metabolic syndrome (MS) of the workers considering some components

\begin{tabular}{|c|c|c|c|c|c|}
\hline \multirow{3}{*}{ Variables } & \multicolumn{4}{|c|}{ MS status } & \multirow{3}{*}{$\mathrm{p}$} \\
\hline & \multicolumn{2}{|c|}{ with MS } & \multicolumn{2}{|c|}{ without MS } & \\
\hline & $\mathrm{n}$ & $\%$ & $\mathrm{n}$ & $\%$ & \\
\hline \multicolumn{6}{|l|}{ Job } \\
\hline office and administrative staff & 51 & 30.1 & 118 & 69.9 & $0.003^{*}$ \\
\hline caterpillar operator & 35 & 56.5 & 27 & 43.5 & \\
\hline driver & 39 & 46.4 & 45 & 53.6 & \\
\hline security & 9 & 28.1 & 23 & 71.9 & \\
\hline controller & 52 & 43.0 & 69 & 57.0 & \\
\hline unqualified - master worker & 67 & 44.4 & 84 & 55.6 & \\
\hline total & 253 & 40.9 & 366 & 59.1 & \\
\hline \multicolumn{6}{|l|}{ Working station } \\
\hline solid waste storage & 110 & 47.4 & 122 & 52.6 & $0.000^{*}$ \\
\hline excavation & 27 & 54.0 & 23 & 46.0 & \\
\hline medical waste & 15 & 45.5 & 18 & 54.5 & \\
\hline administrative office & 32 & 24.6 & 98 & 75.4 & \\
\hline naval services & 17 & 34.7 & 32 & 65.3 & \\
\hline scavenging & 52 & 41.6 & 73 & 58.4 & \\
\hline total & 253 & 40.9 & 366 & 59.1 & \\
\hline \multicolumn{6}{|l|}{ Age groups (years) } \\
\hline$<35$ & 24 & 31.2 & 53 & 68.8 & $0.009^{*}$ \\
\hline $35-44$ & 85 & 47.2 & 95 & 52.8 & \\
\hline$\geq 45$ & 50 & 53.8 & 43 & 46.2 & \\
\hline \multicolumn{6}{|l|}{ Time worked (years) } \\
\hline$<10$ & 120 & 59.1 & 83 & 40.9 & $0.039^{*}$ \\
\hline$\geq 10$ & 71 & 48.6 & 75 & 51.4 & \\
\hline
\end{tabular}

* Chi-square.

Table 5. The metabolic syndrome (MS) status of the workers

\begin{tabular}{|c|c|c|c|c|c|}
\hline \multirow{3}{*}{ Job } & \multicolumn{4}{|c|}{ MS status } & \multirow{3}{*}{$\mathrm{p}$} \\
\hline & \multicolumn{2}{|c|}{ with MS } & \multicolumn{2}{|c|}{ without MS } & \\
\hline & $\mathrm{n}$ & $\%$ & $\mathrm{n}$ & $\%$ & \\
\hline Office and administrative staff & 50 & 29.6 & 119 & 70.4 & $0.000^{*}$ \\
\hline Other workers & 203 & 45.0 & 247 & 55.0 & \\
\hline Total & 253 & 40.9 & 366 & 59.1 & \\
\hline
\end{tabular}


Table 6. Results of logistic regression analysis

\begin{tabular}{lcccccccc}
\hline \multicolumn{1}{c}{ Variables in the Equation } & B & SE & Wald & df & Sig. & OR & \multicolumn{2}{c}{$95 \%$ CI for OR } \\
\hline Reference - office & & & & & & 1.00 & lower & upper \\
Stations other than the office & 0.96 & 0.22 & 18.17 & 1 & 0.000 & 2.60 & 1.68 & 4.04 \\
Reference (< 10 years) & & & & & & 1.00 & & \\
Years worked (> 10 years) & 0.35 & 0.17 & 4.18 & 1 & 0.041 & 1.41 & 1.01 & 1.97 \\
Constant & -1.28 & 0.22 & 33.79 & 1 & 0.000 & 0.28 & & \\
\hline
\end{tabular}

B - Regression co-efficient, SE - Standard error, OR - Odds Ratio.

\section{DISCUSSION}

Metabolic syndrome constitutes a great risk not only for obesity and diabetes mellitus, but also for cardiovascular diseases. There has been a significant increase in metabolic syndrome cases around the world in the last two decades. In this worldwide increase, the effect of industrialization and modern life cannot be denied. Being an important public issue, metabolic syndrome shows differences between not only definitive groups of community but, between different countries as well [12-14].

In one of the studies conducted in Turkey, Onat and Syensoy have found metabolic syndrome prevalence to be $27 \%$ in males. Özşahin et al. have indicated metabolic syndrome prevalence to equal $33.4 \%$ (23.7\% in males, $39.1 \%$ in females). Sanışoğlu et al. have reported metabolic syndrome prevalence on the level of $27.3 \%$ in their study [15-17]. Prevalence of metabolic syndrome has been reported to be $28 \%$ in males according to the research made by METSAR (Turkey Metabolic Syndrome Research Group) [18].

Lohsoonthorn et al. have found metabolic syndrome prevalence to equal $15.2 \%$ among workers in Bangkok. The percentage of males among the population with metabolic syndrome equaled $29.9 \%$.

In a study conducted in Turkey among workers in Izmir Municipality, metabolic syndrome prevalence has been reported to be $4.4 \%$ among those under 35 years of age, $19 \%$ among those between 35 and 44 years of age, $22.7 \%$ among those between 45 and 54 years of age and $44.4 \%$ for those over 55 years of age [19].

In our study, in which we used the NCEP-ATP III diagnostic criteria, metabolic syndrome prevalence was $40.9 \%$. The reason why our result is higher than the Turkey's average could result from the differences in lifestyle and health-related behaviors of solid waste sector workers.

In our study, one of the most important components of metabolic syndrome - i.e. hypertriglyceridemia was the most encountered one (57.7\%). This value was higher than the value found in a study conducted by Sanışoğlu [17]. The percentage of hypertriglyceridemia cases equaled $35 \%$ in the study conducted by Kozan et al. [8]. While a high blood pressure level was the most often encountered abnormality (45\%) in a study completed by Lonsoonthorn, in our study, the triglyceride level was the most frequent one [12]. In the study conducted with workers of Izmir Municipality, the triglyceride component was the most often noted component (47.1\%) [19]. In our study, employees had buffet meals provided by the company to be protected from hazardous effects of their work environment. Employees had sufficient and satisfactory meals, but they could not perform physical exercise. The lack of regular physical exercises led to the accumulation of factors predisposing the subjects to metabolic syndrome.

While no metabolic syndrome component was found in $11.0 \%$ of the participating workers, $23.6 \%$ had three, $15.3 \%$ had four and $1.9 \%$ had five components. In 
the study conducted with employees in Izmir Municipality, the percentage of those who had three components of metabolic syndrome was $12.2 \%$, four components $-4.7 \%$ and five components $-0.9 \%$. In the study by Lansonn, conducted among office employees, in workers with the body mass index of 25 and more, the percentage of those who had three components was $15.2 \%$, while only $1 \%$ of the subjects had five components at the same time [12]. The ratio of components was also found to be higher because of the high prevalence rates of metabolic syndrome in our study.

Our results showed that metabolic syndrome prevalence equaled $31.2 \%$ for subjects under the age of 35 , while it was found to be as high as $53.8 \%$ in those over 45 and older. In Tek Harf study conducted in Turkey, metabolic syndrome prevalence in males between 40 and 49 years of age was found to equal 44\%. The study conducted among workers of İzmir Municipality by Demiral et al. reported that those under the age of 35 had the prevalence rate of $4.4 \%$, while those over 55 years of age had this rate at the level $44.4 \%$ [19]. Lohsoonthorn et al. showed that the metabolic syndrome prevalence was $6.8 \%$ in those under 30 years of age, while the prevalence rate equaled $35.1 \%$ for those over 50 years of age in the study they conducted among workers in Bangkok [12]. The prevalence of metabolic syndrome seemed to be lower in young subjects, and the prevalence rates tended to increase with age. In our study, prevalence rates for both younger and older ages were found to be higher, although prevalence seemed to increase with age compared to other studies. Age is an important factor for metabolic syndrome manifestations and its onset. Meanwhile, in solid waste collection and disposal sector, the risks generated by the nature of the job, the work station and the time already worked also play an important role. In our study, employees who had been working for over 10 years had a 1.41 times higher risk for metabolic syndrome compared to those who had worked for less than 10 years.
Considering the jobs of workers, metabolic syndrome was seen most frequently among caterpillar operators (employees who work as caterpillar operators - all of who worked at the excavation sites). There was a statistically significant difference between the work stations and metabolic syndrome. Employees working in stations other than administrative office had a 2.60 times higher risk for metabolic syndrome compared to those working in the office.

In our study, $92.7 \%$ of office workers were high-school graduates or had higher education. It was noted that among the workers performing mental kind of work, who are better educated, prevalence of metabolic syndrome was lower than in less educated persons performing physical kind of work.

\section{CONCLUSIONS}

Metabolic syndrome prevalence is higher in employees of solid waste collecting and disposal plants compared to the results obtained for the rest of the community. A significant correlation was found between metabolic syndrome distribution in workers and work station, job, age and time already worked. Taking preventive precautions against risks coming from the workplace environment of workers will surely provide important contribution to public and especially occupational health.

\section{REFERENCES}

1. Expert Panel on Detection, Evaluation, and Treatment of High Blood Cholesterol in Adults Executive Summary of the Third Report of the National Cholesterol Education Program (NCEP) Expert Panel on Detection, Evaluation, and Treatment of High Blood Cholesterol in Adults (Adult Treatment Panel III). J Am Med Assoc 2001;285:2486-97.

2. Kylin E. Study on Hypertension-Hyperglycemia-Hyperuricemia Syndrome. Med Leipz 1923;81:105-27 [in German]. 
3. Reaven GM. Role of Insulin Resistance in Human Disease. Diabetes 1988;37:1595-607.

4. Ferrannini E, Haffner SM, Mitchell BD, Stern MP. Hyperinsulinaemia. The Key Feature of a Cardiovascular and Metabolic Syndrome. Diabetologia 1991;34(6):416-22.

5. Isomaa B. Cardiovascular Morbidity and Mortality Associated with the Metabolic Syndrome. Diabetes Care 2001;24(4): 683-9.

6. Lakka HM, Laaksonen DE, Lakka TA, Niskanen LK, Kumpusalo E, Tuomilehto J, et al. The Metabolic Syndrome and Total and Cardiovascular Disease Mortality in Middle-Aged Men. J Am Med Assoc 2002;288:2709-16.

7. Zeller M, Steg PG, Ravisy J, Laurent Y, Janin-Manificat L, Huillier I L, et al. Prevalence and Impact of Metabolic Syndrome on Hospital Outcomes in Acute Myocardial Infarction. Arch Intern Med 2005;165:1192-8.

8. Kozan O, Oguz A, Erol C, Şenocak M, Öngen Z, Çelik S, et al. The Frequency of Metabolic Syndrome in Turkey. Eur J Clin Nutr 2007;61:548-53.

9. Dağdelen S, Yıldırım T, Erbaş T. Global Confusion on the Diagnostic Criteria for Metabolic Syndrome: What Is the Point that Guidelines Can Not Agree? Anatolian J Cardiol 2008;8:149-53.

10. Third report of the National Cholesterol Education Program (NCEP). Expert Panel on Detection, Evaluation and Treatment of High Blood Cholesterol in Adults. (Adult Treatment Panel III). Final Report. Circulation J Am Med Assoc 2002;106:3143-241.
11. Handelsman Y. Metabolic Syndrome Pathophysiology and Clinical Presentation. Toxicol Pathol 2009;37:18-20.

12. Lohsoonthorn V, Lertmaharit SA, Williams MA. Prevalence of Metabolic Syndrome among Professional and Office Workers in Bangkok, Thailand. J Med Assoc Thai 2007;90:9.

13. Cameron AJ, Shaw JE, Zimmet PZ. The Metabolic Syndrome: Prevalence in Worldwide Populations. Endocrinol Metab Clin North Am 2004;33:351-75.

14. Shiwaku K, Nogi A, Kitajima K, Anuurad E, Enkhmaa B, Yamasaki M, et al. Prevalence of Metabolic Syndrome in Asian Workers. J Occup Health 2005;47:126-35.

15. Özşahin AK, Gökcel A, Sezgin N, Akbaba M, Güvener N, Ozisik L, et al. Prevalence of the Metabolic Syndrome in a Turkish Adult Population. Diabet Nutr Metab 2004;17:230-4.

16. Onat A, Sansoy V. Metabolic Syndrome, Major Culprit of Coronary Disease Among Turks: Its Prevalence and Impact on Coronary Risk. Arch Turk Soc Cardiol 2002;30:8-15.

17. Sanışoğlu SY, Oktenli C, Hasimi A, Yokusoglu M, Ugurlu M. Prevalence of Metabolic syndrome-related disorders in a large adult population in Turkey. BMC Public Health 2006;6:92.

18. Onat A, Ceyhan K, Basar O, Erer B, Toprak S, Sansoy V. Metabolic syndrome: Major Impaction Coronary Risk in a Population with Low Cholesterol Levels - A Prospective and CrossSectional Evaluation. Atherosclerosis 2002;165(2):285-92.

19. Demiral Y, Soysal A, Bilgin AC, Kılıc B, Unal B, Ucku R, et al. The Association of job strain with coronary heart disease and metabolic syndrome in municipal workers in Turkey. J Occup Health 2006;48:332-8.

This work is available in Open Access model and licensed under a Creative Commons Attribution-NonCommercial 3.0 Poland License - http://creativecommons.org/ licenses/by-nc/3.0/pl/deed.en. 